This item was submitted to Loughborough's Research Repository by the author.

Items in Figshare are protected by copyright, with all rights reserved, unless otherwise indicated.

Performance measurements at varying irradiance spectrum, intensity and module temperature of amorphous silicon solar cells

PLEASE CITE THE PUBLISHED VERSION

http://dx.doi.org/10.1109/PVSC.2010.5617110

PUBLISHER

(C) IEEE

VERSION

VoR (Version of Record)

LICENCE

CC BY-NC-ND 4.0

REPOSITORY RECORD

Bliss, Martin, Thomas R. Betts, and Ralph Gottschalg. 2019. "Performance Measurements at Varying Irradiance Spectrum, Intensity and Module Temperature of Amorphous Silicon Solar Cells". figshare. https://hdl.handle.net/2134/7923. 
This item was submitted to Loughborough's Institutional Repository (https://dspace.lboro.ac.uk/) by the author and is made available under the following Creative Commons Licence conditions.

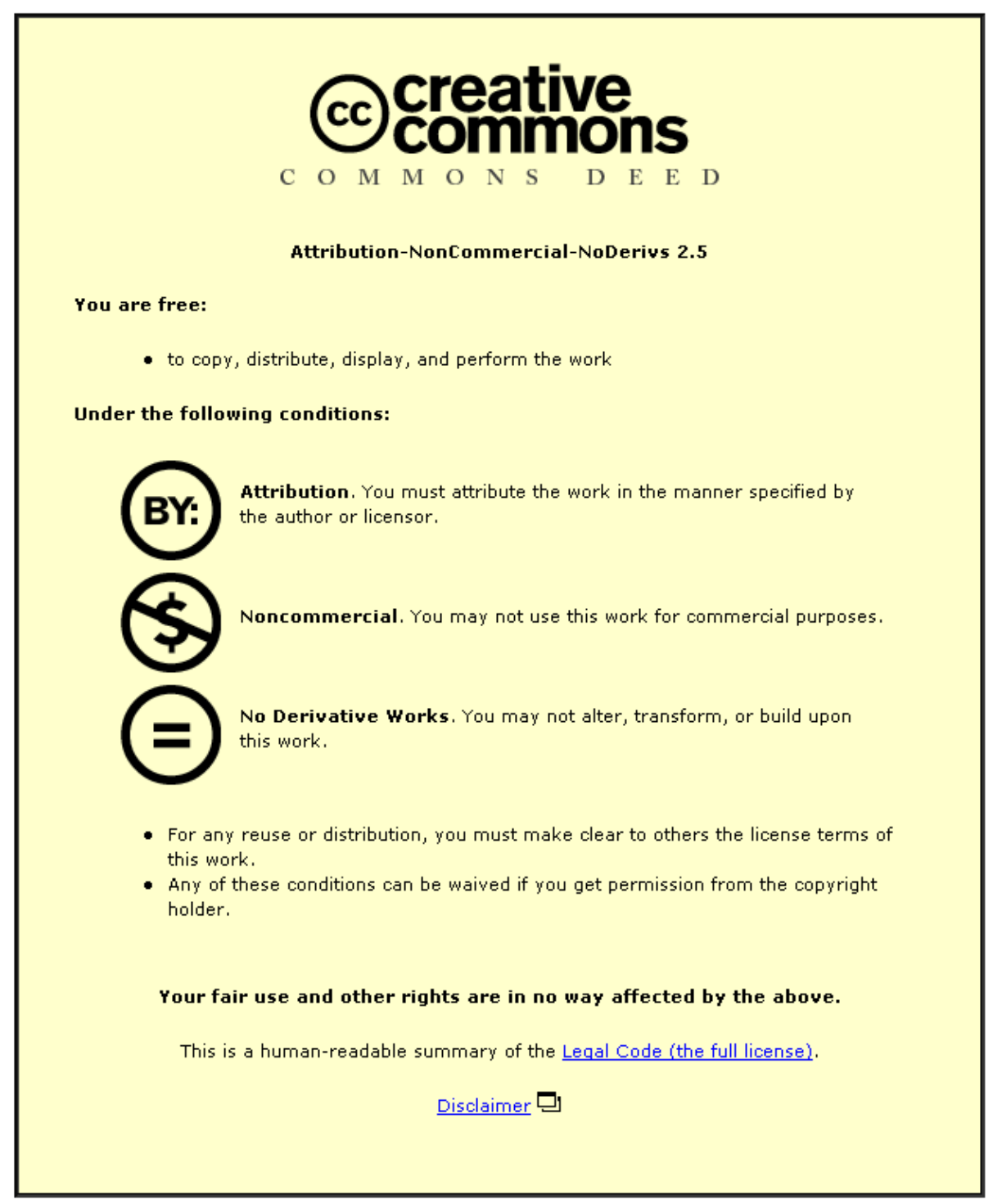

For the full text of this licence, please go to: http://creativecommons.org/licenses/by-nc-nd/2.5/ 


\title{
PERFORMANCE MEASUREMENTS AT VARYING IRRADIANCE SPECTRUM, INTENSITY AND MODULE TEMPERATURE OF AMORPHOUS SILICON SOLAR CELLS
}

\author{
M. Bliss*, T.R. Betts, R. Gottschalg \\ Centre for Renewable Energy Systems Technology (CREST), Department of Electronic and Electrical Engineering, \\ Loughborough University, Loughborough, Leicestershire, LE11 3TU, UK
}

\begin{abstract}
This paper demonstrates photovoltaic (PV) device performance measurements for energy rating and energy yield calculation derived indoors with an LED-based solar simulator prototype under varying irradiance (G), temperature $(T)$ and spectrum $(E)$, opening the possibility for much faster and more accurate energy yield prediction than previously possible from measurements acquired either indoors or outdoors, with the additional inclusion of spectral influences.
\end{abstract}

The main aspects of the LED-based solar simulator used are described briefly and the measurement method with its requirements is explained in detail. Also presented are the first performance measurements made with an amorphous silicon solar cell; measuring the spectral effects reported in outdoor measurements for the first time in the laboratory. Results show a good agreement with previously reported spectral effects from outdoor measurements and underline the importance to consider all three environmental vectors (irradiance, spectrum and device temperature) for energy yield focused measurements.

\section{INTRODUCTION}

Energy yield calculations of $\mathrm{PV}$ devices are gaining importance for PV users as, unlike power rating under standard test conditions (STC), they take into account variations of environmental conditions. This is leading to more complete information on device performance in different climatic conditions and ultimately can improve the determination of the financial return of an installation.

Currently, for characterization for energy yield prediction, devices are measured outdoors or indoors in a matrix of different irradiances $(G)$ and temperatures $(T)$. Energy rating derived from outdoor measurements can be accurate [1], but may take a long time to acquire, because many environmental factors change only on longer time scales. Furthermore, separating the influencing effects (i.e. spectrum, temperature, irradiance and angle of incidence) on the device performance for a site independent evaluation is difficult and adds additional uncertainties that furthermore have a site dependency [2]. Indoor measurement methods need correction of the G-T measurements for the effects of spectrum (E), which can again lead to large uncertainties in the energy prediction as the drivers for these influences are strongly correlated, especially when working with multi-junction or wide band gap solar cells ([3] and [4]). To solve this problem, one would need to measure the device in conditions as experienced in real operation with varying irradiance spectrum, light intensity and device temperature, which to date has been possible only outdoors. CREST has developed an LED-based solar simulator that can closely reproduce realistic outdoor conditions with varying spectrum, irradiance and temperature. Thus, it meets requirements to carry out device characterization measurements in a G-T-E performance matrix for more accurate energy yield prediction. Indoors, this can be done in a much shorter time frame than is possible outdoors and opens possibilities to keep energy rating of photovoltaic devices up-to-date, in line with product development timeframes for new devices.

In the following, the LED-based solar simulator hardware is briefly described and the measurement method with its requirements is explained. Performance matrix measurements are made on a single-junction amorphous silicon mini module. The results confirm reports of spectral effects in outdoor operation. The analysis also demonstrates a strong correlation between the performance influencing factors $G, T$ and $E$, and thus the need for carrying out these measurements for an accurate energy yield prediction.

\section{MEASUREMENT METHOD}

The measurement method used consists of 3 main steps (Fig. 1): defining measurement ranges, adjusting simulator light output to reference spectra and measuring the GTmatrix at each spectrum.

When defining the measurement ranges it is important to use measurement points in the G-T-E matrix that are of most interest and generally seen outdoors. This is important, as the number of measurements can be very large and is dependent on the number of different spectra, intensities and temperatures chosen.

Prior to making a G-T matrix measurement set at a given spectrum, the simulator output spectrum is adjusted by separately altering the intensity of each of the available 
light sources. The required intensity of each light source color can be acquired with help of a fitting algorithm that minimizes the deviation between the required sunlight spectrum and the spectrum in the simulator. Once the required intensities are known, the light spectrum can be set with the help of the external quantum efficiency (EQE) curve of the device under test or, if a closely matched reference cell is available, with help of the reference cell's $E Q E$. If the test device has more than one junction it is important that the junction current balance remains the same as it would experience under the reference spectrum.

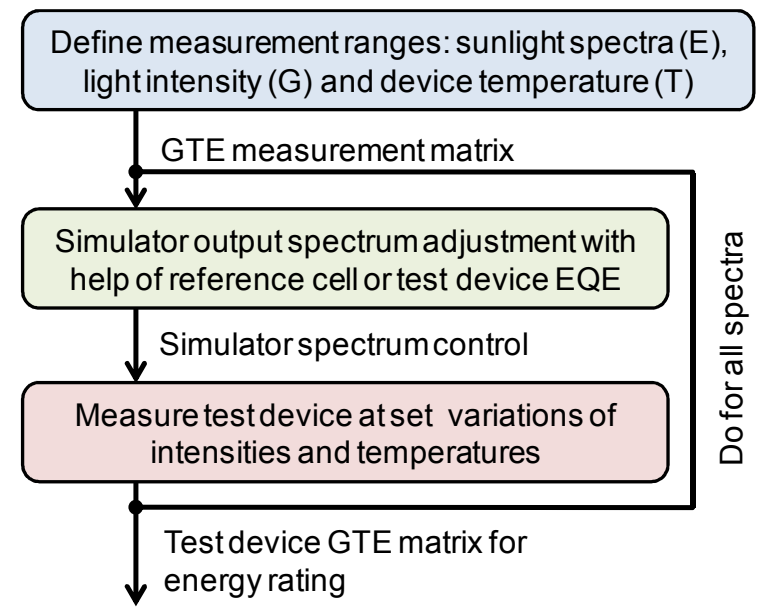

Fig. 1 Basic method for measuring a G-T-E device performance matrix

Once the light spectrum has been adjusted, a light intensity and temperature (G-T) matrix can be measured. An important note is that the light sources in the simulator should have minimal change in their output spectra with varying intensity. If this is not the case, a readjustment of the simulator spectrum or a mismatch correction will be required for each intensity step.

\section{MEASUREMENT SYSTEM AND CONFIGURATION}

All performance measurements have been carried out using the LED-based solar simulator prototype developed at CREST. A detailed description of the solar simulator with a classification analysis can be found in [5] and [6]. In summary, the system uses 8 different LED colors and halogen light sources, all separately controllable, thus delivering a very flexible spectral output and light intensity. For the control of the device temperature a peltier cooling system has been implemented. This is capable of regulating device temperature from freezing point to $80^{\circ} \mathrm{C}$ in $0.1^{\circ} \mathrm{C}$ steps. In practice, only temperatures down to $15^{\circ} \mathrm{C}$ are used as condensation may occur at temperatures below the dew point, which typically is around this value.

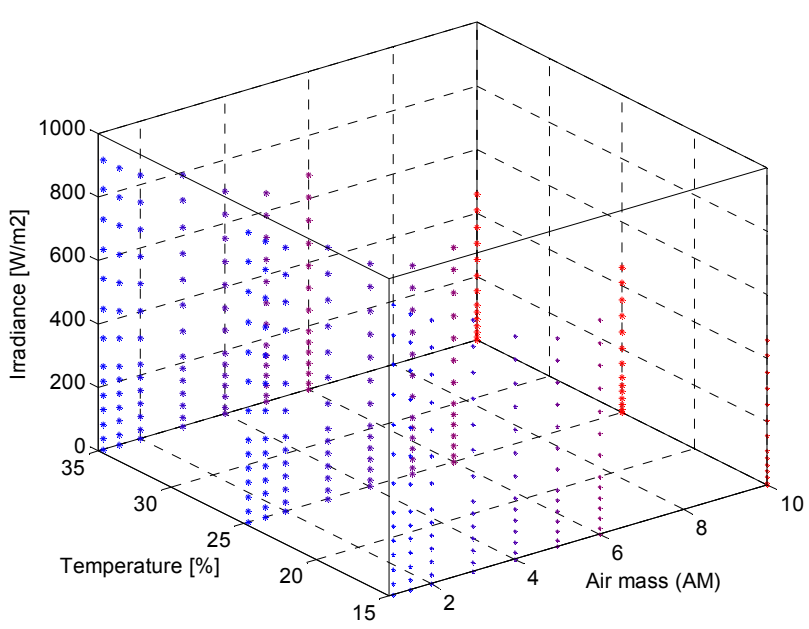

Fig. 2 Selected measurement points in the G-T-E performance matrix

\begin{tabular}{ccc}
\hline \hline Solar spectrum & \multicolumn{2}{c}{ Irradiance [W/m2] } \\
As standard & $\begin{array}{c}\text { Maximum in } \\
\text { Solar simulator }\end{array}$ \\
\hline AM1.1 & 1080 & 915 \\
AM1.5 & 1021 & 872 \\
AM2.0 & 943 & 831 \\
AM3.0 & 806 & 794 \\
AM4.0 & 699 & 702 \\
AM5.0 & 613 & 657 \\
AM6.0 & 543 & 676 \\
AM10.0 & 289 & 458 \\
\hline \hline
\end{tabular}

Table 1 Irradiance comparison of the reference sunlight spectra used and the maximum achievable in the solar simulator; reference spectra are total inplane spectra simulated with SMARTS on a tracking plane, with all other input parameters as in IEC60904-3 [7].

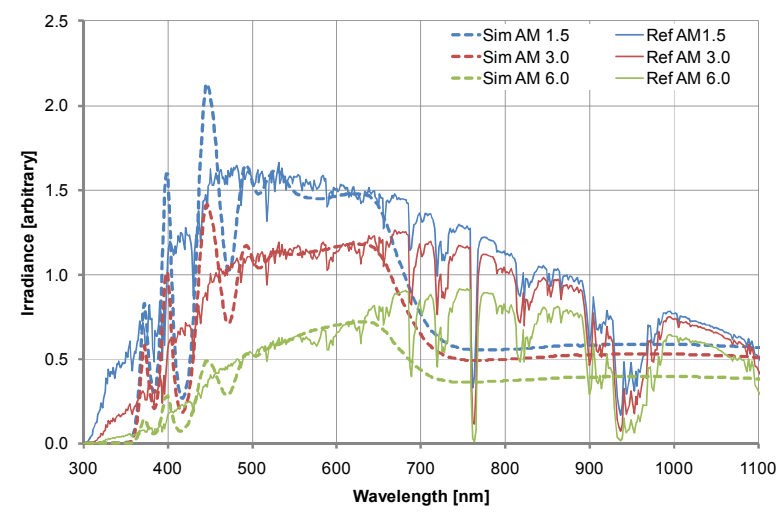

Fig. 3 Reference and simulator spectra of 3 of the 8 selected spectra; all output spectra used are within class $B$ when applying the same wavelength bins and allowable deviations as in the IEC $60904-9$ standard [8] 
The PV device tested is a $50 \times 50 \mathrm{~mm}^{2}$ single-junction amorphous silicon mini module with 3 cells. The G-T-E measurement matrix is built with 288 points (Fig. 2) consisting of 8 different spectra (AM1.1 to AM10) measured at 3 device temperatures $\left(15^{\circ} \mathrm{C}\right.$ to $\left.35^{\circ} \mathrm{C}\right)$ and 12 intensities from $5 \%$ to $100 \%$ of the maximum irradiance achievable in the solar simulator (Table 1) under the chosen reference sunlight conditions (Fig. 3).

\section{MEASUREMENT RESULTS}

\section{Influences of Irradiance Spectrum and Light Intensity}

PV device performance influences due to changes in spectrum are today largely neglected in energy yield predictions. With the ability of the simulator to reproduce different sunlight spectra with good accuracy it is also possible to directly investigate the changes due to spectra and, as is visible in the following figures, neglecting spectral influences even on single-junction amorphous devices can lead to large uncertainties in the final energy yield prediction.

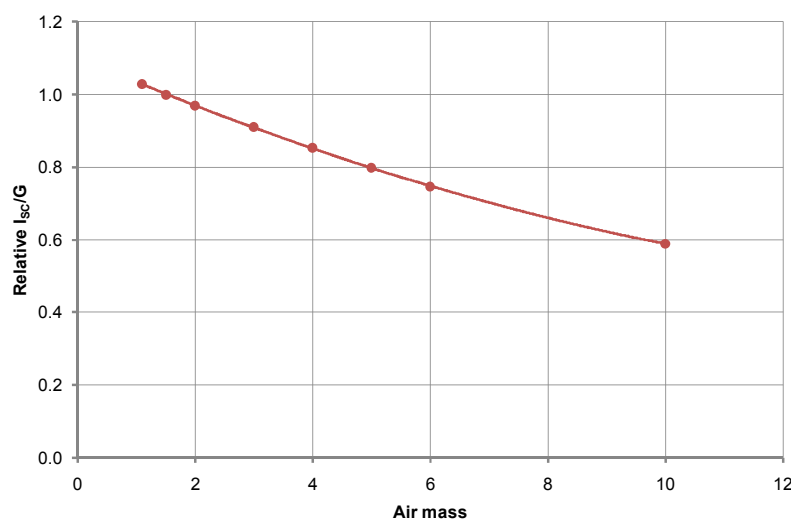

Fig. 4 Relative Isc/G versus air mass (AM) normalized to the measurement at AM1.5 spectrum

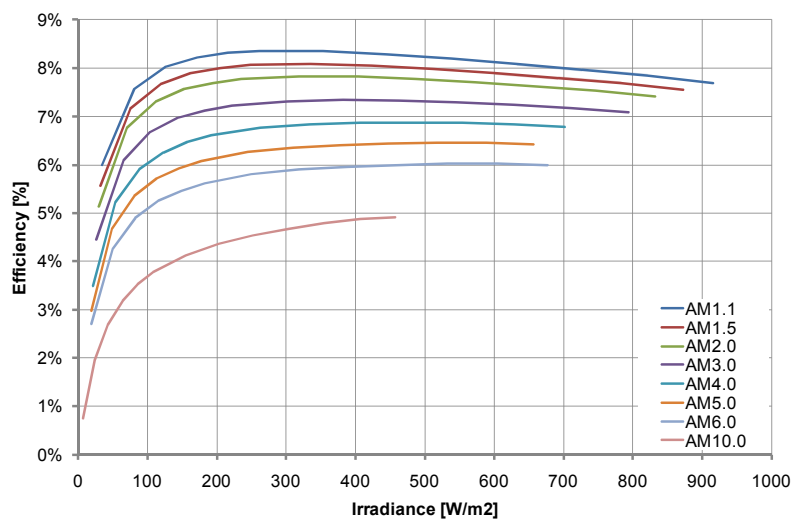

Fig. 5 Efficiency versus $\mathbf{G}$ at varying air mass
As illustrated in Figure 4, the short circuit current over irradiance $\left(\mathrm{I}_{S C} / \mathrm{G}\right)$ is significantly affected by variations of spectrum and drops down with increasing air mass. This is due to the spectral response of amorphous silicon solar cells being in the in the ultraviolet to red $(\sim 300-750 \mathrm{~nm})$ region where the sunlight spectra (and simulator light spectra) changes the most with air mass. Similar behavior has also been extracted from outdoor measurements and reported in [9], [10] and [11]. This drop of relative short circuit current has also a direct effect on the device efficiency (Fig. 5).

Fig. 6 shows the open circuit voltage $\left(V_{O C}\right)$ versus $I_{s c}$ at different spectra. Voltage behavior is logarithmic and not visibly influenced by different spectra. Plotting $V_{O C}$ versus $G$ (Fig. 7) shows a very different result, clearly showing the drop of $V_{O C}$ with increasing air mass. This is due to the significantly lower relative $\mathrm{I}_{\mathrm{SC}} / \mathrm{G}$ at high air mass, previously shown in Fig. 4.

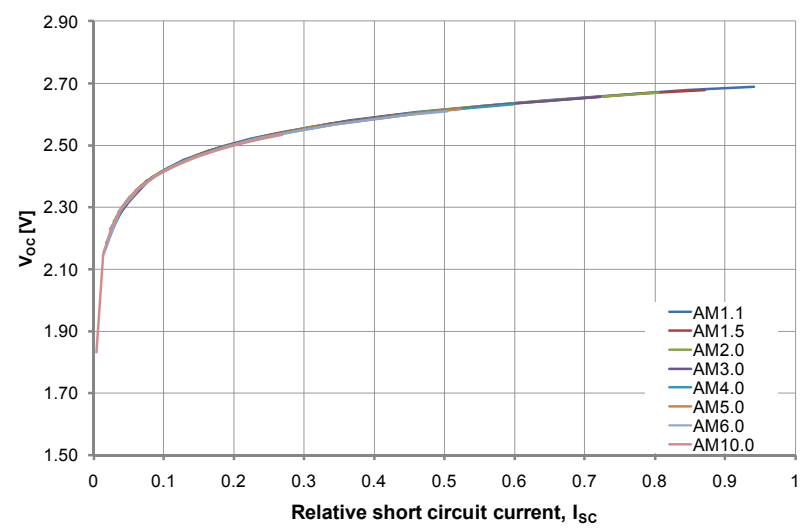

Fig. $6 \quad V_{o c}$ versus relative Isc at varying air mass; clearly visible the strong correlation of $V_{\mathrm{OC}}$ to $\mathrm{I}_{\mathrm{sc}}$, no changes with light spectrum have been observed

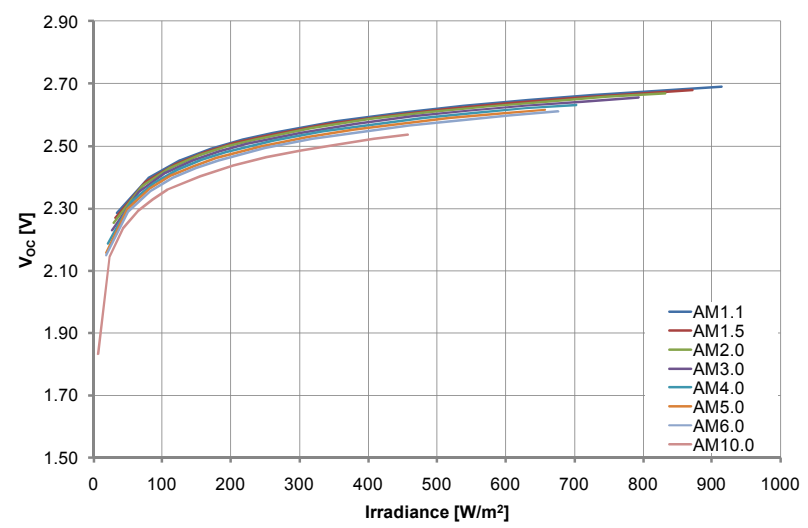

Fig. 7 Voc versus irradiance $(G)$ at varying air mass; Voc drops with increasing air mass due to the significant decrease in relative $I_{S c} / G$ 
Unlike the observations for crystalline silicon solar cells (c$\mathrm{Si}$ ), the a-Si device fill factor (FF) and maximum power point voltage $\left(\mathrm{V}_{\mathrm{MP}}\right)$ are also affected by changes in spectrum as illustrated in Fig. 8 and Fig. 9. At high air mass, the fill factor peaks at very low light intensities of around $80 \mathrm{~W} / \mathrm{m}^{2}$. This peak shifts to higher intensities with increasing air mass $\left(150 \mathrm{~W} / \mathrm{m}^{2}\right.$ at $\left.\mathrm{AM} 10\right)$. Furthermore the peak FF and the drop of FF with increasing irradiance are reduced with increasing air mass. Similar trends can be seen in $V_{M P}$ with the difference that the peak point is shifted further into the high irradiance region.

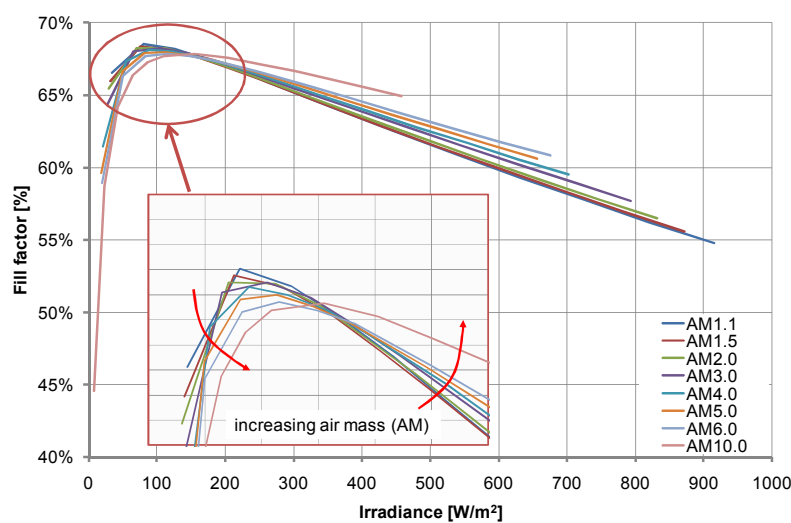

Fig. 8 FF versus $\mathbf{G}$ at varying air mass

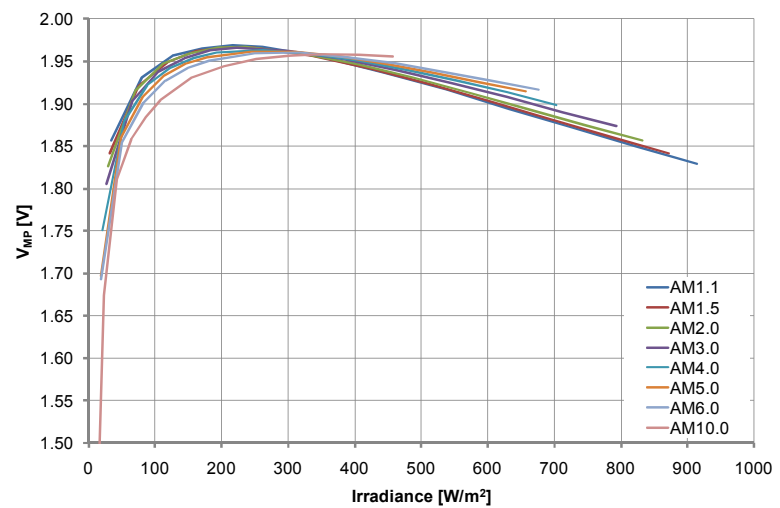

Fig. $9 \quad V_{M P}$ versus $G$ at varying air mass

Plotting FF and $V_{M P}$ (Fig. 10 and Fig. 11) versus the short circuit of the device reveals that the unusual behavior is again due to the large reduction in relative $\mathrm{ISC}_{\mathrm{SC}} / \mathrm{G}$ with increasing higher air mass shown in Fig. 4. Plotting against Isc reveals a more generally reported behavior of amorphous silicon solar cells: device fill factor is benefitting from blue-rich, low air mass spectra [4].

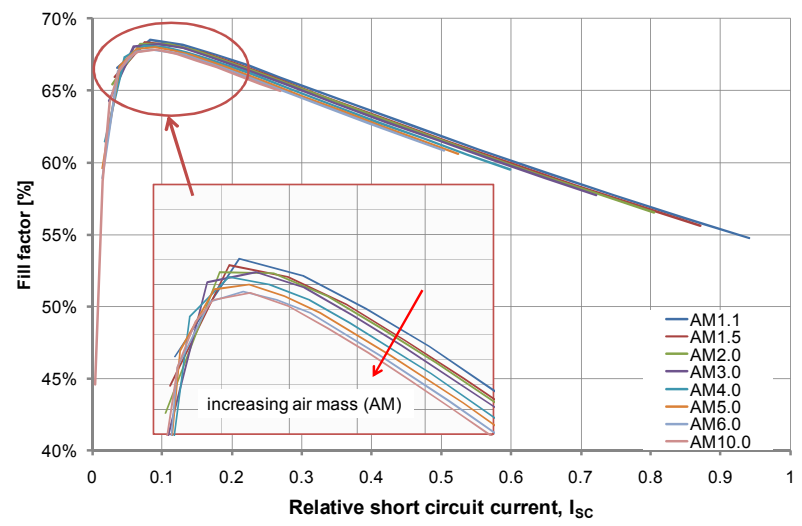

Fig. 10 FF versus relative $I_{S C}$ at varying air mass

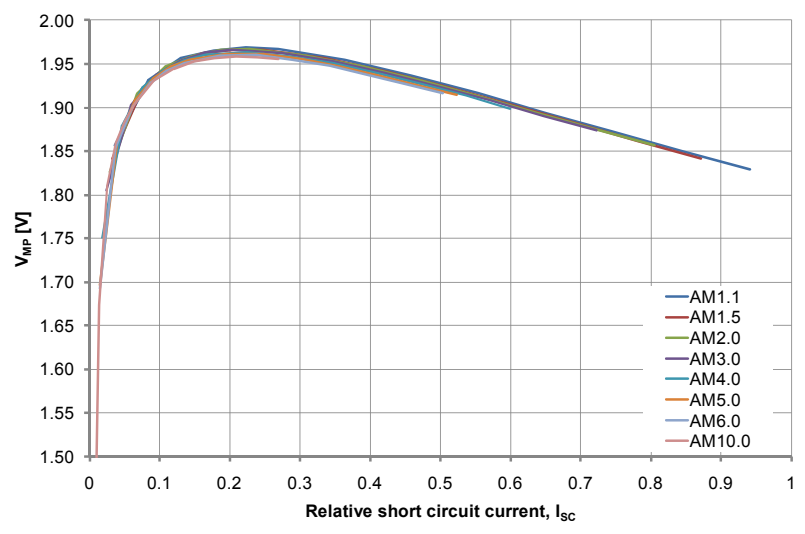

Fig. $11 V_{M P}$ versus relative $I_{S C}$ at varying air mass

\section{Temperature Influences}

The influences of temperature and light intensity on the test device's efficiency are shown in Fig. 14 (last page). At AM1.5 spectrum, efficiency peaks at around $300 \mathrm{~W} / \mathrm{m}^{2}$ and then decreases with increasing irradiance. This pattern is followed by the fill factor as well, with the main difference being an earlier peak at around $80 \mathrm{~W} / \mathrm{m}^{2}$.

The temperature coefficients extracted from the recorded IV-curve parameters are illustrated in Fig. 12. In most cases the absolute temperature coefficients are larger at low light intensities. However, this is not the case for the fill factor, which benefits from higher irradiances and temperatures. Nevertheless, the actual power output decreases slightly. Since measurements have been done at varying spectrum, coefficients have also been extracted from measurements under spectra other than AM 1.5. Clearly visible are the increasing temperature influences on $\mathrm{FF}$ and $\mathrm{I}_{\mathrm{SC}}$ and a reduction in the $\mathrm{P}_{\mathrm{MP}}$ temperature coefficient. Temperature influences on $V_{O C}$ are not affected by spectrum for this device. Such behavior has not yet been reported to the authors' knowledge. The reason may be that it is very difficult to extract such influences from outdoor data and indoors varying spectra could not be produced. 


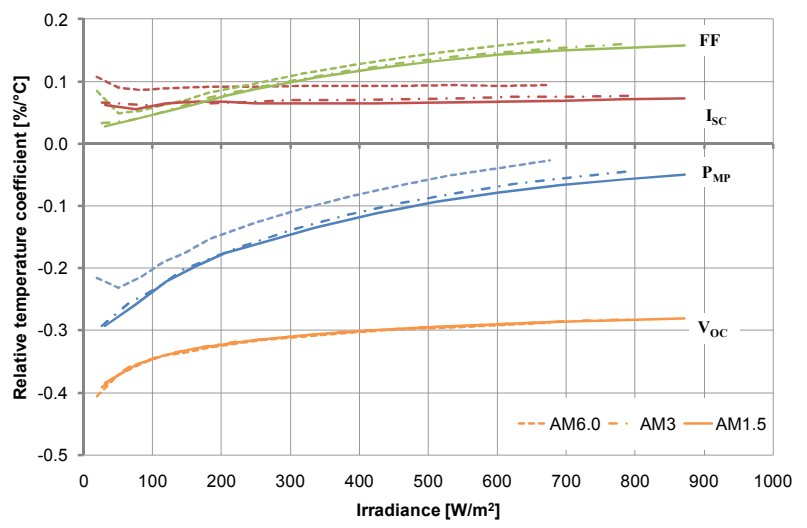

Fig. 12 Temperature coefficients of the device parameters over light intensity at different air mass; extracted from G-T-E performance measurements over the range of $15^{\circ} \mathrm{C}$ to $35^{\circ} \mathrm{C}$, illustrated as values relative to the performance at $25^{\circ} \mathrm{C}$

During extraction of temperature coefficients it was found that the coefficients of some performance parameters extracted from data points in the range of $15^{\circ} \mathrm{C}$ to $25^{\circ} \mathrm{C}$ were significantly different to the ones extracted from $25^{\circ} \mathrm{C}$ to $35^{\circ} \mathrm{C}$. To further examine this phenomenon, a set of new measurements was carried out repeatedly at full light intensity at AM 1.5 spectrum conditions over a greater range of temperatures from $15^{\circ} \mathrm{C}$ to $45^{\circ} \mathrm{C}$. Device temperature was ramped up and down in $5^{\circ} \mathrm{C}$ steps to also detect any eventual hysteresis effects that could indicate further secondary effects as such as thermal annealing. The time difference between every measurement is approximate 5 minutes. This includes regulation of the device to the new temperature setting and $\sim 3.5$ minutes settling time for stabilization. All results are illustrated in Fig. 13.

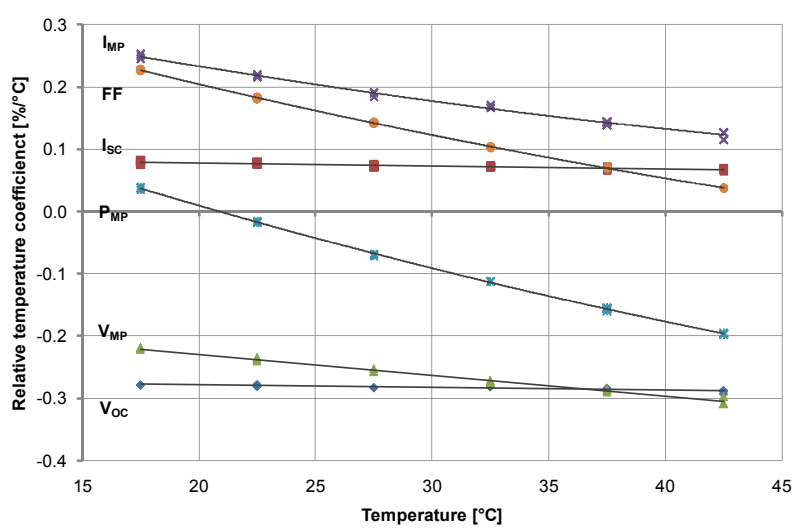

Fig. 13 Changes in parameter temperature coefficients versus device temperature itself; measured at AM 1.5 spectrum conditions, coefficients relative to values at $25^{\circ} \mathrm{C}$, all 3 measurement temperature ramps up and down are plotted here and resulted in the same parameters and behavior without hysteresis
Clearly visible in the graph is that all temperature coefficients, except for $I_{S C}$ and $V_{O C}$ are affected by temperature itself. The drop of temperature coefficient in $\mathrm{I}_{\mathrm{MP}}$ and the relative increase in $\mathrm{V}_{\mathrm{MP}}$ temperature coefficient with temperature have an overall drop in the FF coefficient with temperature and an increasingly negative temperature coefficient in maximum power as consequence.

It is interesting to note that the temperature coefficient recorded for $\mathrm{P}_{\mathrm{MP}}$ is positive at temperatures below $\sim 21^{\circ} \mathrm{C}$. This means that the device is not as usually seen performing better at low temperatures and it seems that the amorphous silicon device tested has an optimum operation temperature at this point with maximum power and efficiency.

At this point in time it is not known if the observed temperature behavior is specific for this a-Si test device or if it is generally seen. Further research will need to be carried out here. If this is a general case, then energy yield calculation might need to incorporate non-linear temperature effects as the change in $\mathrm{P}_{\mathrm{MP}}$ temperature coefficient is very significant.

\section{CONCLUSIONS}

A method for complete indoor characterization of $\mathrm{PV}$ devices has been presented. The first G-T-E performance matrix measurement results derived indoors on a thin-film amorphous mini module show very different behavior to crystalline silicon cells. The device showed significant spectral influences not only on Isc but also on FF and $V_{M P}$. Additionally, temperature coefficients seem to be dependent on irradiance, spectrum and the device temperature itself and are thus nonlinear in all respects. This not only shows that a GTE-matrix can be measured but also that measurements at varying spectrum, irradiance and device temperature are highly important to be able make an accurate assumption of the device performance at a specific location.

G-T-E performance matrix measurements open a new dimension for device characterization as it is the first time that spectral effects on devices can be measured directly, i.e. without having to calculate from quantum efficiency curves. This is a very promising start for a more accurate and much faster energy yield prediction especially of thinfilm and multi-junction devices, than has been possible to date outdoors or indoors. This also means that energy rating can keep up-to-date with product development timeframes.

\section{ACKNOWLEDGEMENT}

This work has been supported by the UK Engineering and Physical Sciences Research Council (EPSRC) grant number EP/D078431/1. 


\section{REFERENCES}

[1] G. Friesen, et al., "Intercomparison of different energy prediction methods within the European project "performance" - results on the 2 nd round robin," in Proceedings of the 24th European Photovoltaic Solar Energy Conference, Hamburg, Germany, 2009, pp. 3189 - 3197.

[2] M. B. Strobel, et al., "Uncertainty in Photovoltaic performance parameters - dependence on location and material," Solar Energy Mater. Solar Cells, vol. 93, pp. 1124-1128, 6, 2009.

[3] R. Gottschalg, et al., "The effect of spectral variations on the performance parameters of single and double junction amorphous silicon solar cells," Solar Energy Mater. Solar Cells, vol. 85, pp. 415-428, 1/31, 2005.

[4] R. Rüther, G. Kleiss and K. Reiche, "Spectral effects on amorphous silicon solar module fill factors," Solar Energy Mater. Solar Cells, vol. 71, pp. 375-385, 2/15, 2002.

[5] M. Bliss, T.R. Betts and R. Gottschalg, "An LEDbased photovoltaic measurement system with variable spectrum and flash speed," Solar Energy Mater. Solar Cells, vol. 93, pp. 825-830, 6, 2009.
[6] M. Bliss, et al., "Towards a higher power, all LED solar simulator closely matching realistic solar spectra", in Proceedings of the 24th European Photovoltaic Solar Energy Conference, Hamburg, Germany, 2009, pp. 3321 - 3326

[7] IEC 60904-3 2009 Photovoltaic devices - Part 3: Measurement Principles for Terrestrial PV Solar Devices with Reference Spectral Irradiance Data.

[8] IEC 60904-9 2007 Photovoltaic devices - part 9: Solar simulator performance requirements.

[9] D. L. King, J. A. Kratochvil and W. E. Boyson, "Stabilization and performance characteristics of commercial amorphous-silicon PV modules," in Photovoltaic Specialists Conference, 2000. Conference Record of the Twenty-Eighth IEEE, 2000, pp. 1446-1449.

[10] R. P. Kenny, et al., "Performance of thin film PV modules," Thin Solid Films, vol. 511-512, pp. 663672, 7/26, 2006.

[11] J. Merten and J. Andreu, "Clear separation of seasonal effects on the performance of amorphous silicon solar modules by outdoor I/V-measurements," Solar Energy Mater. Solar Cells, vol. 52, pp. 11-25, 3/16, 1998.
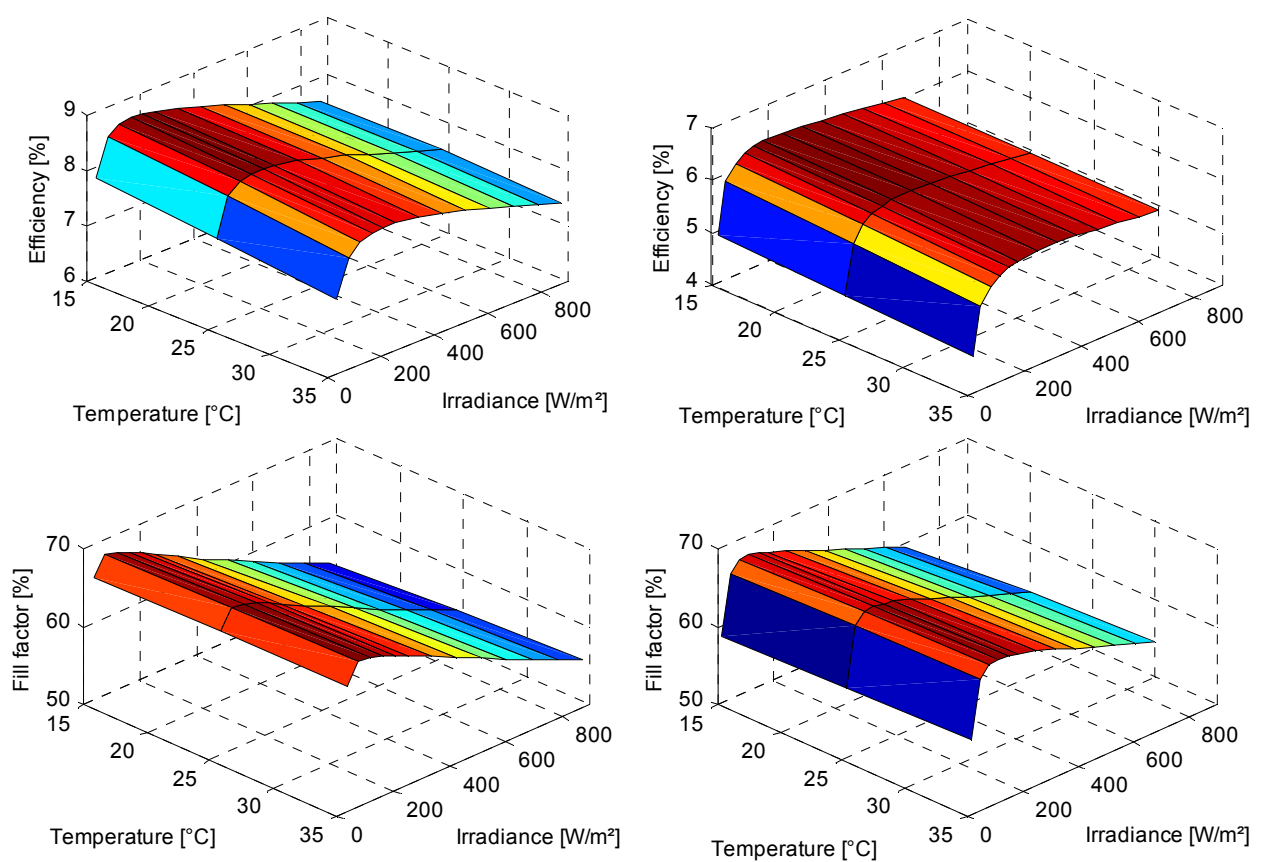

Fig. 14 Top: 3D plot of Efficiency versus G-T at AM 1.5 (left) and AM 6 (right) spectrum; Bottom: Plot of fill factor versus G-T at same spectra, AM 1.5 (left) and AM 6 (right); clearly visible are the larger influences of irradiance at AM 1.5 spectrum on efficiency and fill factor, at AM 6 the drop of efficiency and fill factor relative to irradiance is less (although in practice, not such a large range of irradiance will be observed) 